\title{
Magnesium Concentration in Asthma Patients in Gaza Strip - Case Control Study
}

\author{
Kholoud Abed El-Fattah Omran*, Yusuf Khaled Elzyyan, Emad Atef Saqer, \\ Abed Elraheem Nasrallah Safi
}

Department of Medical Science, University Collage of Science and Technology, Gaza, Palestine

Email address:

shafaamrschool@hotmail.com (K. A. El-Fattah O.), yousefelzyyan@gmail.com (Y. K. Elzyyan), abodsafi131295@gmail.com (A. E. N. Safi), emadsaqer@gmail.com (E. A. Saqer)

${ }^{*}$ Corresponding author

\section{To cite this article:}

Kholoud Abed El-Fattah Omran, Yusuf Khaled Elzyyan, Emad Atef Saqer, Abed Elraheem Nasrallah Safi. Magnesium Concentration in Asthma Patients in Gaza Strip - Case Control Study. Journal of Chemical, Environmental and Biological Engineering.

Vol. 3, No. 1, 2019, pp. 1-7. doi: 10.11648/j.jcebe.20190301.11

Received: October 13, 2018; Accepted: April 22, 2019; Published: May 10, 2019

\begin{abstract}
Asthma is a common heterogeneous inflammatory chronic disorder of the airways. It is "defined by the history of respiratory symptoms such as wheeze, shortness of breath, chest tightness, and cough that vary over time and in intensity often with variable expiratory airflow limitation can be demonstrated". According to the World Health Organization, asthma is the most common chronic respiratory disorder among children. Magnesium deficiency is associated with increased contractility of smooth muscle cells. Since contractility of bronchial smooth muscle is important in patients with asthma, magnesium deficiency could negatively influence the clinical condition. On the basis of the critical role of $\mathrm{Mg}$ in the regulation of bronchial smooth muscle, studies have shown that intravenous application or inhalation of Mg could alleviate symptoms in asthmatic patient. In the present study which was a case-control study plasma concentration of magnesium in 50 asthma patients (27 male, 23 female) in Gaza strip were measured and compare with 50 healthy non-asthmatic controls (37 male, 13 female). Questionnaire interview was applied. The concentrations of $\mathrm{Mg}$ were measured by using spectrophotometer. The mean $\pm \mathrm{SD}$ magnesium level in plasma was $1.52 \pm 0.4 \mathrm{mg} / \mathrm{dl}, 2.02 \pm 0.27 \mathrm{mg} / \mathrm{dl}$ in cases and control respectively, there was statically significant difference between cases and control $(\mathrm{P}=0.000)$. Thirty-nine $(78 \%)$ of cases had $\mathrm{Mg}$ deficiency while seven (14\%) of control had Mg deficiency. Seven (14\%) of patient had sensitivity to dairy product ( $\mathrm{P}=0.031)$. Forty-five $(90 \%)$ of patient had health problems especially frequent inflammation of eyes, nose and throat $(\mathrm{P}=0.000)$. There were significant differences between cases and control in family history of disease $(\mathrm{P}=0.000)$. The finding of this study demonstrate that asthmatics patient had lower plasma magnesium level compared to healthy controls in Gaza strip.
\end{abstract}

Keywords: Asthma, Magnesium, Chronic, Gaza Strip

\section{Introduction}

Asthma is a common heterogeneous inflammatory chronic disorder of the airways. It is "defined by the history of respiratory symptoms such as wheeze, shortness of breath, chest tightness, and cough that vary over time and in intensity often with variable expiratory airflow limitation can be demonstrated" [1, 2]. According to the World Health Organization, asthma is the most common chronic respiratory disorder among children [3]. Magnesium, atomic number 12 and mass $24.32 \mathrm{Da}$, is the fourth most abundant cation in the body and the second most abundant cation in intracellular fluid. It is a cofactor for about 300 cellular enzymes and has an important role in energy metabolism, participating in phosphate-transfer reactions involving ATP and nucleotide triphosphates. Although the physiological role of magnesium is primarily intracellular, the majority of experimental data concerning this element is from extracellular sources, primarily blood [4]. The concentration of magnesium in plasma is of value for assessing acute changes in magnesium status. The treatment of patients with cardiac arrhythmias, acute onset of seizures, diabetic ketoacidosis, etc., requires knowledge of the magnesium concentration in plasma. 
Magnesium deficiency has been implicated as a factor in numerous chronic diseases: hypertension, coronary heart disease, premenstrual syndrome [5-7]. $\mathrm{Mg}$ is involved in pathophysiological reactions related to asthma. $\mathrm{Mg}$ has been shown to relax bronchial smooth muscle in vitro and to Broncho dilate asthmatic airways in vivo $[8,9]$, inhibition of release of acetylcholine from cholinergic nerve terminals and of histamine from mast cells, promotion of nitric oxide synthesis and prostacyclin generation are all associated with changes in intracellular $\mathrm{Mg}$ concentrations $[10,11]$. On the basis of the critical role of $\mathrm{Mg}$ in the regulation of bronchial smooth muscle cell contractility via its effects on calcium transport activation and phosphorylation/dephosphorylation of intracellular reactions, it has been proposed that the intracellular $\mathrm{Mg}$ content may determine the excitability of these cells. Several studies have shown that intravenous application or inhalation of $\mathrm{Mg}$ could alleviate symptoms in acute and stable asthma [12].

New surveys are needed to update asthma trends. The prevalence of diagnosed asthma in the urban and rural areas in west bank in Palestine were $4.2 \%$ and $2.8 \%$ respectively [13]. In Arab countries, there is low research productivity about bronchial asthma, and in Palestine most studies reported only the prevalence, symptoms and geographic variation of asthma and asthma symptoms. To date there is no studies in west bank and Gaza strip about the association between asthma and $\mathrm{mg}$ concentration level. There are several studies on serum $\mathrm{Mg}$ levels in asthma patients which show that hypomagnesemia is commonly seen in asthmatics [14-16], the present study will provide us a clear picture about the $\mathrm{Mg}$ status on asthmatic patients in Gaza strip and compare them with normal people, this study may give us a new strategy for control of asthma by using $\mathrm{Mg}$. also this study will help us in understand the relation between asthma and lifestyle and environmental determinants among asthma patients in Gaza strip.

\section{Materials and Methods}

This study was a case control carried out from April, 2017 to October, 2017 included 50 patients aged (18-60) years with chronic stable bronchial asthma during their regular follow up in the outpatient clinic from chest department in El-Shifa, European, Nasser hospital in Gaza strip, Palestine, Patient diagnosed as asthmatics according to Global initiative for asthma [3], in addition 50 age and sex matched healthy individuals were included as a control group.

\subsection{Exclusion Criteria}

People who had chest infection/chest disease, Smokers, any disease known to cause hypomagnesemia (renal disease, diabetes, hypertension, cardiac disease, diuretic use, current pregnancy, breast feeding, recent convalescence, menstrual disorders which require treatment, bone disease, gastrointestinal disease, hormonal disorders, metabolic disorders, recent infections, anorexia, dysphagia), People who had received $\mathrm{Mg}$ containing drugs, patients who received any rescue treatment for asthma within 24 hours before inclusion.

\subsection{Ethical Considerations}

Participants were recruited into this study after obtaining a written informed consent from each of them. Also, an ethical approval was obtained from the Palestinian Ministry of Health.

\subsection{Sample Collection and Storage}

About $5 \mathrm{ml}$ of venous blood samples collected from the study population in lithium heparin tubes and then spun at $4000 \mathrm{rpm}$ for 10 minutes to obtain plasma samples which were kept at $-20^{\circ}$ until analyzed for $\mathrm{Mg}$ level. Study population was asked to filled out a questionnaire related to their health habits by using a meeting interview for filling in a questionnaire. $\mathrm{Mg}$ levels of the patients were determined using Magnesium XL FS kit, range: 1.8-2.6 mg/dl.

\subsection{Statistical Analysis}

The data was entered, stored and analyzed by personal computer using the statistical package for Social Sciences (SPSS) version 20. Independent Samples T-test and Chi square test use to compare between cases and controls. $\mathrm{P}$ value $<0.05$ was consider statistically significant.

\section{Results}

The study population comprised of $50 \%$ asthma patient (case group); (27 (54\%) male, 23 (46\%) female and 50\% control group; (37 (74\%) male, 13 (26\%) female (figure 1). The difference between male and females of cases and control was significance $(\mathrm{P}=0.037)$. Age classification showed that $24(48 \%)$ cases and $29(58 \%)$ control were $18-30$ years old, $7(14 \%)$ cases, $3(6 \%)$ control were $31-40$ years old, $11(22 \%)$ cases and control were $41-50$ years old and 8 (16\%) cases, $7(14 \%)$ control were 51-60 years old. The difference between cases and control in terms of age distribution was not significant $\mathrm{P}>0.05$. Mean ages of cases and control were $35.2 \pm 12.9$ and $33 \pm 13.4$ years old respectively. The independent sample t-test also showed no significant difference between mean ages of cases and control $(\mathrm{t}=0.834, \mathrm{p}=0.407)$. Twenty-seven $(54 \%)$ and 22 $(44 \%)$ of cases and control were married respectively compared to twenty-three (46\%) and $28(56 \%)$ of cases and control were single respectively. The difference between the two groups was not significance $\mathrm{P}>0.05$, (Table 1 ).

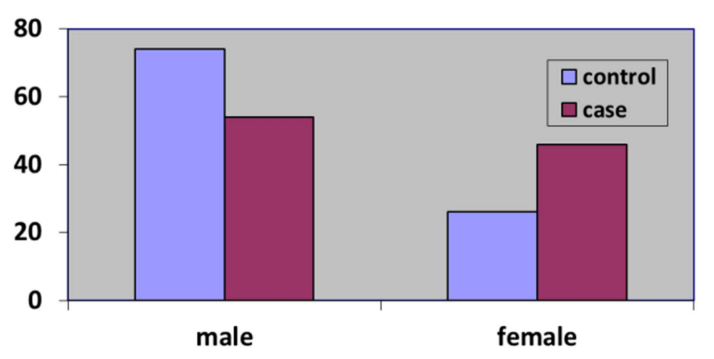

Figure 1. Gender of the study population. 
Table 1. Personal profile of the study population.

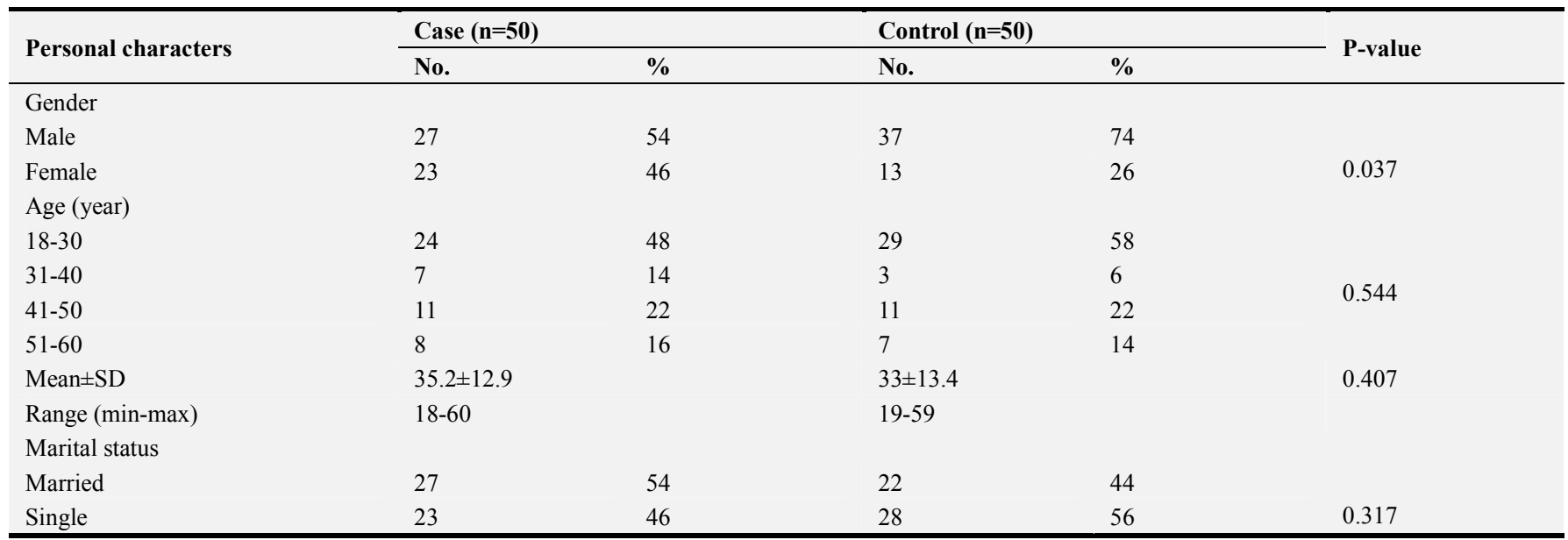

$\mathrm{P}>0.05$ : not significant, $\mathrm{P}<0.05$ : significant

Table 2. Smoking and the study population.

\begin{tabular}{|c|c|c|c|c|c|}
\hline \multirow{2}{*}{ Smoking habits } & \multicolumn{2}{|c|}{ Case $(n=50)$} & \multicolumn{2}{|c|}{ Control $(n=50)$} & \multirow{2}{*}{ P-value } \\
\hline & No. & $\%$ & No. & $\%$ & \\
\hline Non-smokers & 34 & 68 & 42 & 84 & \multirow{3}{*}{0.061} \\
\hline Smokers & 16 & 32 & 8 & 16 & \\
\hline Less than 3 years & 6 & 12 & 6 & 12 & \\
\hline 3- 7 years & 5 & 10 & 1 & 2 & \multirow{2}{*}{0.109} \\
\hline More than 7 years & 5 & 10 & 1 & 2 & \\
\hline Not negative smokers & 27 & 54 & 20 & 40 & \multirow{2}{*}{0.161} \\
\hline Negative smokers & 23 & 46 & 30 & 60 & \\
\hline
\end{tabular}

$\mathrm{P}>0.05$ : not significant, $\mathrm{P}<0.05$ : significant

Smoking habits of the study population is illustrated in table 2. The nonsmokers were $34(68 \%)$ cases, $42(84 \%)$ control and $16(32 \%)$ cases, $8(16 \%)$ control were smoked in the past and stopped, the difference between two groups was not significant $\mathrm{P}>0.05$. Smokers people that smoked less than three years were $6(12 \%)$, for cases and control, People that smoked 3-7 years and more than 7 years were $5(10 \%), 1$ $(2 \%)$ for cases and control. The difference between these two groups were not significant $\mathrm{P}>0.05 .23(46 \%), 30(60 \%)$ were negative smokers of the study population respectively, 27 (54\%) cases, 20 (40\%) control were not negative smokers. The difference between two groups were not significant.

Concerning Food sensitivity, health problems and family history of the study population table 3 shows that $32(64 \%)$ cases and $42(48 \%)$ control were not sensitive to food, 18 $(36 \%)$ cases, $8(16 \%)$ control were sensitive to food and there were no significant differences between two groups $(\mathrm{P}=0.823)$. People who sensitive to dairy product, eggs, fish, (dairy product, eggs and fish), others were 7 (14\%) cases, 1 (2\%) control, $2(4 \%)$ cases, $0(0 \%)$ control, $4(8 \%)$ cases, 0 $(0 \%)$ control, $1(2 \%)$ cases, 2 (2\%) control, $4(8 \%)$ cases, 5 $(5 \%)$ control respectively, and there was significant differences between the two groups $(\mathrm{P}=0.031)$. $5(10 \%)$ cases, $42(84 \%)$ control were not have health problems, and $45(90 \%)$ cases, $8(16 \%)$ control were have health problems with significant differences between two groups $(\mathrm{P}=0.000)$. People who had health problems (frequent inflammation (eye, nose, throat), gland diseases, migraine headache, all three health problems) were $25(50 \%)$ cases, $1(2 \%)$ control, $1(2 \%)$ cases, 2 (4\%) control, $6(12 \%)$ cases, 5 (10\%) control, $13(26 \%)$ cases, $0(0 \%)$ control respectively. The most frequent health problem for cases was inflammations for eyes, nose and throat. 14 (28\%) cases, $45(90 \%)$ control had family history of asthma and $36(72 \%)$ cases, $5(10 \%)$ control had not family history of asthma the difference between two groups was statistically significant $(\mathrm{P}=0.000)$.

Table 3. Food sensitivity, health problems and family history of study population.

\begin{tabular}{lllll}
\hline \multirow{2}{*}{ Food sensitivity } & Case (n=50) & & \multicolumn{2}{c}{ Control (n=50) } \\
\cline { 2 - 4 } & No & \% & No & \\
\hline Sensitivity to food & & & & \\
No & 32 & 64 & 42 & 84 \\
Yes & 18 & 36 & 8 & 16 \\
Dairy products & 7 & 14 & 0.823 & 0 \\
Eggs & 2 & 4 & 0.031 & 0 \\
\hline
\end{tabular}




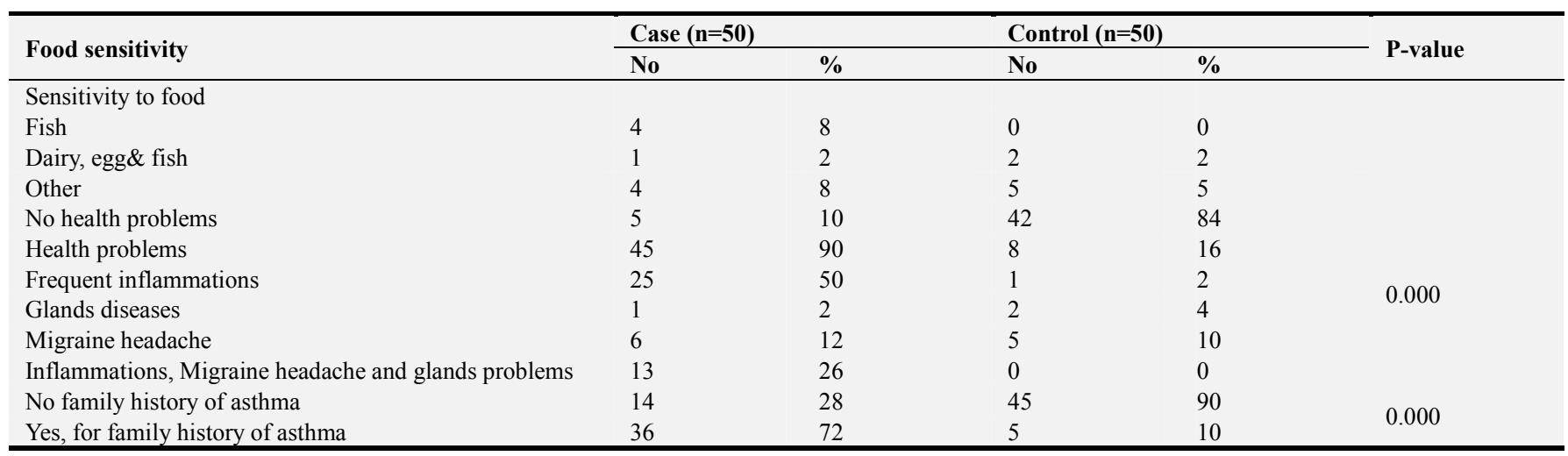

$\mathrm{P}>0.05$ : not significant, $\mathrm{P}<0.05$ : significant

Table 4 shows the average plasma $\mathrm{Mg}$ levels in control and cases. There was a significant decrease in the mean level of $\mathrm{Mg}$ in cases compared to controls (1.52 \pm 0.4 vs $2.02 \pm 0.27$ $\mathrm{mg} / \mathrm{dl}, \%$ difference $=0.493, \mathrm{P}=0.000$ ). Table 5 shows that, 39 $(78 \%), 7(14 \%)$ plasma Mg deficiency in cases and control respectively and $11(22 \%), 43(86 \%)$ of cases and control respectively were have plasma $\mathrm{Mg}$ normal levels. The difference between two groups were statistically significant $(\mathrm{P}=0.000)$.

Table 4. Plasma Mg levels of the study population.

\begin{tabular}{lllll}
\hline \multirow{2}{*}{ Parameter } & Case $(\mathbf{n}=\mathbf{5 0})$ & Control $(\mathbf{n}=\mathbf{5 0})$ & \multirow{2}{*}{ \% Difference } & \multirow{2}{*}{ P-value } \\
\cline { 2 - 3 } & Mean \pm SD & Mean \pm SD & \multirow{2}{*}{0.493} & 0.000 \\
\hline Mg level $(\mathrm{mg} / \mathrm{dl})$ & $1.52 \pm 0.4$ & $2.02 \pm 0.27$ & & \multirow{2}{*}{$(1.20-2.81)$} \\
(min-max) & $(0.86-2.50)$ & & & \\
\hline
\end{tabular}

Assay range: $1.8-2.6 \mathrm{mg} / \mathrm{dl}, \mathrm{P}>0.05$ : not significant, $\mathrm{P}<0.05$ : significant

Table 5. Plasma Mg deficiency and Normal levels of study population.

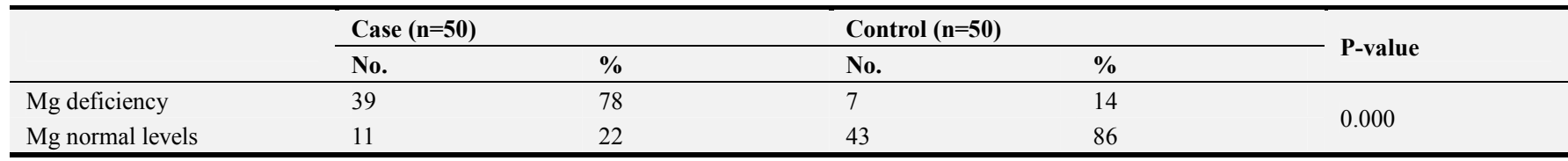

$\mathrm{P}>0.05$ : not significant, $\mathrm{P}<0.05$ : significant

Frequent asthma symptoms in asthmas patients and $\mathrm{Mg}$ levels were illustrated in Table 6, Patient of asthma with normal $\mathrm{Mg}$ level that have daily asthma attack symptoms were $8(16 \%)$, while $1(2 \%)$ have these symptoms more than twice weekly and $2(4 \%)$ have it sporadically. Patient of asthma attack with low Mg level that have daily asthma attack symptoms were $29(58 \%)$, while $1(2 \%)$ have these symptoms more than twice weekly, less than twice weekly, weekly and $7(14 \%)$ have it sporadically. The difference between two groups of patients were not statistically significant $(\mathrm{P}=0.830)$. The average of wake up because of asthma attack were $10(20 \%)$ every night, $1(2 \%) 2-3$ times weekly for patient with normal $\mathrm{Mg}$ level, while the average of wake up because of asthma were $36(72 \%)$ every night, 1 (2\%) 2-3 times weekly, 2 (4\%) more than 5 times weekly for patient with low $\mathrm{Mg}$ level, and there was no significant difference between two groups of patient $(\mathrm{P}=0.477)$.

Table 6. Frequent asthma symptoms in asthmas patients and $\mathrm{Mg}$ level.

\begin{tabular}{|c|c|c|c|c|c|}
\hline \multirow{2}{*}{ Frequent symptoms } & \multicolumn{2}{|c|}{ Patient with Mg normal level (n=11) } & \multicolumn{2}{|c|}{ Patient with Mg deficiency $(n=39)$} & \multirow{2}{*}{ P-value } \\
\hline & No & $\%$ & No & $\%$ & \\
\hline \multicolumn{5}{|c|}{ How many times you have asthmatic symptoms } & \multirow{6}{*}{0.830} \\
\hline Daily & 8 & 16 & 29 & 58 & \\
\hline More than 2 times weekly & 1 & 2 & 1 & 2 & \\
\hline Less than 2 times weekly & 0 & 0 & 1 & 2 & \\
\hline Weekly & 0 & 0 & 1 & 2 & \\
\hline Sporadic & 2 & 4 & 7 & 14 & \\
\hline \multicolumn{5}{|c|}{ Average of wake up at night because of asthma } & \multirow{4}{*}{0.477} \\
\hline Every night & 10 & 20 & 36 & 72 & \\
\hline 2-3 times weekly & 1 & 2 & 1 & 2 & \\
\hline$>5$ times weekly & 0 & 0 & 2 & 4 & \\
\hline
\end{tabular}

$\mathrm{P}>0.05$ : not significant, $\mathrm{P}<0.05$ : significant 


\section{Discussion}

Approximately 38.4 million Americans have been diagnosed with asthma by a health care professional during their lifetime and an estimated 300 million people worldwide suffer from asthma, with 250,000 annual deaths [17]. The prevalence of asthma increased 75\% from 1980-1994 and asthma rates in children under the age of 5 years increased more than $160 \%$ from 1980-1994 [18]. It is currently estimated that by 2025 , the number of people with asthma will grow by 100 million. Data on asthma were limited to annual reports emerged from the Palestinian ministry of health and few studies have been focused on asthma. The present work is the first to assess $\mathrm{Mg}$ levels in asthma patient in Gaza strip. There were few studies of adult-onset asthma that ascertain incident, rather than prevalent, asthma cases. Most studies focusing on risk factors for prevalent asthma cannot distinguish whether an exposure causes new cases of asthma or adversely affects persons with pre-existing disease, resulting in a longer duration of symptoms. As such, the present study makes a significant contribution to the literature. There was no statistical relationship between current smoking and asthma risk. This agree with study reported by Eisner, 2002 [19]. Our result disagrees with study said that Tobacco smoking may be associated with an increased incidence rate of adult-onset asthma, especially among women [20]. Result in the present study showed that asthma patient had higher sensitivity to dairy products and then fish, others types of food and eggs. Although food allergy is not typically an etiology of asthma, an asthmatic patient with food allergy may have higher rates of morbidity and mortality associated with the asthma. Asthma is rarely a manifestation of food allergy alone, but the symptoms can be seen with allergic reactions to foods. When milk is consumed it temporarily thickens saliva in the mouth, a sensation that many people mistake for respiratory mucus production. This sensation is not due to increased production of mucus, it results from the creamy texture of the fluid itself and will also occur with other liquids of similar 'thicknesses. There is no clinical evidence to suggest that reducing or stopping consumption of milk and dairy products will help relieve symptoms of asthma. Asthma symptoms are usually caused by substances that are inhaled (such as dust mite allergens), not those that are eaten. Some people may cough after drinking cold milk, but this is usually due to breathing in cool air while they drink. Warming the milk first can help [21]. According to a study of 25 patients reported in Jean Carper's book, Food: Your Miracle Medicine, after following a milkand meat-free diet for only four months, 71 percent of the patients experienced an improvement in their asthma symptoms. After a year, asthma improved in 92 percent of the patients [22]. With regard to health problems our study demonstrated that $50 \%$ of cases were affected by frequent inflammation of the eye, nose and throat and $26 \%$ were had all these health problem include Inflammations, Migraine headache and glands problems this was logical for asthma patient because airflow obstruction, bronchial hyper responsiveness, and inflammation. The dominant feature that leads to clinical symptoms is smooth muscle contraction and inflammation, which results in narrowing of the airway and obstruction. Numerous triggers can induce bronchoconstriction, including allergic responses, respiratory infections, exercise, irritants, and non-steroidal antiinflammatory drugs in select patients. Persistent inflammation in the airway may lead to structural changes, such as mucus hypersecretion, smooth muscle hyperplasia, sub epithelial fibrosis, blood vessel proliferation, and infiltration of inflammatory cells. This result agrees with all asthma articles. Regarding family history, the present data indicated that family history is a risk factor of asthma. Such finding is in accordance with that found by Liu et al., 2009 [23] and Davoodi et al., 2015 [24]. Result presented in this study revealed that mean level of $\mathrm{Mg}$ was significantly decreased in asthma patients compared to healthy normal controls. This findings in agreement with that observed by Oladipo et al., 2003 [25], Agin and Darjani, 2005 [26], Ali et al, 2015 [16] and Shaikh et al., 2016 [14]. However, Wang et al., 2007 [27] reported that there were no associations between asthma prevalence, dietary magnesium and serum magnesium concentration. Another study by Valk et al., 1993 [28], reported that magnesium level in plasma in asthmatic patients did not differ significantly from those of the healthy controls. The discrepancy in Magnesium level may related to different experimental protocols, however this point needs further investigation. $\mathrm{Mg}$ deficiency has several effects on asthma and its clinical presentations. It is mast cell stabilizer results in bronchoconstriction due to increasing airway hyperactivity and hyper responsiveness through increased acetylcholine production at cholinergic nerve ending and improves pulmonary functions. Medications that are prescribed in asthma divided into two broad groups, antiinflammatory agents as glucocorticoid and bronchodilator agents as beta-2 agonists and theophylline. Receiving these drugs for long times especially its over use by the patients in acute states may cause depletion of $\mathrm{Mg}$ in human through intracellular shift and urinary excretion [29]. Low dietary intake of $\mathrm{Mg}$ is associated with impaired lung function, bronchial hyperactivity and wheezing [30]. Results of this study reveal that hypomagnesaemia in asthmatic patients in Gaza strip is higher as compared to healthy normal people. When related to average of frequent asthma attack symptoms $58 \%$ of patient with $\mathrm{Mg}$ deficiency were suffer from asthma attack symptoms daily, and $72 \%$ of them had asthma symptoms attack every night but there were no significance differences between asthma patient with normal $\mathrm{Mg}$ levels and asthma patient with $\mathrm{Mg}$ deficiency, this result may be due to small sample of asthma patients $n=50$. Improvement of $\mathrm{Mg}$ deficiency through $\mathrm{Mg}$ supplement may be effective in asthma symptoms, reducing risk of hospitalization, and achieving better therapeutic results, but further investigation is needed to complete this hypothesis. This result in agreement with Alamoudi, 2000 [31], who reported that Low 
serum $\mathrm{Mg}$ level causes increased hospitalization (40\%), It is mast cell stabilizer results in bronchoconstriction due to increasing airway hyperactivity and hyper-responsiveness through increased acetylcholine production at cholinergic nerve ending and improves pulmonary functions. Other study by Daliparty, et al., 2018 [32] revealed that Serum Mg levels have a direct correlation with the level of control in asthma. Knightly, et al. 2017 [33] and Irazuzta, et al, 2017 [34] showed that treatment with $\mathrm{MgSO}_{4}$ as an adjunctive therapy, while corticosteroids and beta agonist remain the primary acute therapeutic agents reduces the odds of hospital admissions without significant side effects or harm.

\section{Conclusions}

Results of this study reveal that hypomagnesaemia in asthmatic patients in Gaza strip is higher as compared to healthy non-asthmatic control and the differences between two groups were statistically significant. Benefits of magnesium in the treatment of asthma have not been clearly established yet. However, understanding Mg homeostasis and possible side effects in the body is essential for $\mathrm{Mg}$ to be included in definite recommendations as supportive treatment in asthma patients. Studies that would be performed in larger patient groups of adults with asthma using more advanced testing methods are needed. Improvement of $\mathrm{Mg}$ deficiency through $\mathrm{Mg}$ supplement or increase intake of magnesiumrich foods such as whole grains products, green vegetables and soybean products, may be effective in asthma symptoms, reducing risk of hospitalization, and achieving better therapeutic results, but further investigation is needed to complete this hypothesis.

\section{Acknowledgements}

The authors are grateful to all participants for their cooperation and gratefully acknowledge to Mr. Mohammed Jaber MSc, researcher at the University Collage of Science and Technology-Medical Department in Gaza strip, Palestine for his contribution in the laboratory part of this study.

\section{References}

[1] Reddel, H. K., Bateman, E. D., Becker, A., Boulet, L. P., Cruz, A. A., Drazen, J. M.,... \& Lemanske, R. F. (2015). A summary of the new GINA strategy: a roadmap to asthma control. European Respiratory Journal, 46 (3), 622-639.

[2] Asthma GI. Global Strategy for Asthma Management and Prevention: GINA; 2018. Available from: http://www.ginasthma.org/. [Last accessed on 2018 Nov 16].

[3] Global Initiative for Asthma, (2008). Global strategy for asthma management and prevention. Available at: www.Ginasthma.org. last accessed, September, 2017.

[4] Elin, R. (1987). Assessment of magnesium status. Clinical chemistry, vol. 33, no. 11.

[5] Seelig, MS. (1981). Magnesium requirements in human nutrition. Magnesium Bull; 3: 26-47.

[6] Mellinghoff, K. \& van Lessen, W. (1949). Magnesiumcalcium Bilanz bei Inanition. Dtach Arch Kiln Med; 194: 28593.

[7] Mellinghoff, K. (1949). Magnesium stoffwechsel Storungen bel Inanition. Dtsch Arch Klin Med; 195: 475-80.

[8] Spivey WH., Skobeloff EM. and Levin RM. (1990). Levin RM. Effect of magnesium chloride on rabbit bronchial smooth muscle. Ann Emerg Med; 19 (10): 1107-12.

[9] Bloch, H. Silverman, R. Mancherje, N. Grant, S. Jagminas, L. \& Scharf SM. (1995). Intravenous magnesium sulfate as an adjunct in the treatment of acute asthma. Chest; 107 (6): 157681 .

[10] Hill, J. Micklewright, A. Lewis, S. \& Britton, J, (1997). Investigation of the effect of short-term change in dietary magnesium intake in asthma. Eur Respir J; 10 (10): 2225-9.

[11] Ishizaka, K. Tomioka, H. \& Ishizaka, T. (1970). Mechanisms of passive sensitization. I. Presence of $\operatorname{IgE}$ and $\operatorname{IgG}$ molecules on human leukocytes. J Immunol; 105 (6): 1459-67.

[12] Cepelak, I. \& Cvorisce, D. (1997). Magnezij. Biochem Med; 7 (34): 93-107.

[13] Hasan M. Gofin R. \& Bar-Yishay E. (2009): Urbanization and the Risk of Asthma Among Schoolchildren in the Palestinian Authority, Volume 37, 2000 - Issue 4.

[14] Shaikh, M. N., Malapati, B. R., Gokani, R., Patel, B., \& Chatriwala, M. (2016). Serum Magnesium and Vitamin D Levels as Indicators of Asthma Severity. Pulmonary Medicine, 2016.

[15] Lee, S. H., Song, W. J., Park, H. W., Kim, S. H., Park, H. K., Kim, S. H.,... \& Choi, B. W. (2017). Serum micronutrients levels and clinical features of elderly asthmatics. Allergy, Asthma \& Respiratory Disease, 5 (4), 223-227.

[16] Ali, A. Bakr, R. Yousif, M. Foad, R. (2015): Assessment of serum magnesium level in patients with bronchial asthma, 4 (13), 27-32.

[17] Weiss, K. B., Gergen, P. J., \& Wagener, D. K. (1993). Breathing better or wheezing worse? The changing epidemiolgy of asthma morbidity and mortality. Annual review of public health, 14 (1).

[18] Mannino, D. M., Homa, D. M., Pertowski, C. A., Ashizawa, A., Nixon, L. L., Johnson, C. A.,... \& Kang, D. S. (1998). Surveillance for asthma-United States, 1960-1995. MMWr CDC Surveill Summ, 47 (1), 1-27.

[19] Eisner M. (2002): American Journal of Respiratory and Critical Care Medicine; Vol. 165, No. 11.

[20] Torén K. Hermansson BA. (1999): Incidence rate of adultonset asthma in relation to age, sex, atopy and smoking: a Swedish population-based study of 15813 adults; 3 (3), 192-7.

[21] Nurmatov, U., Devereux, G., \& Sheikh, A. (2011). Nutrients and foods for the primary prevention of asthma and allergy: systematic review and meta-analysis. Journal of Allergy and Clinical Immunology, 127 (3), 724-733.

[22] Edqvist, J., \& Hassan, M. (2013). Protein and Energy Intake in Children with Cow's Milk Protein Allergy: The results of three-day estimated food records in Swedish children 2-11 years of age compared to control group. 
[23] Liu, T. Valdez, R. Yoon, R. Crocker, R. Moonesinghe, R. \& Khoury, M. (2009): The association between family history of asthma and the prevalence of asthma among US adults: National Health and Nutrition Examination Survey, 11, 323328.

[24] Davoodi, P. Mahesh, D. Holla, A. \&Ramachandra, N. (2015): Family history \& the risk for adult onset asthma, 141 (3): 361-363.

[25] Oladipo, O. Chukwu, C. Ajala, M. (2003): Plasma magnesium in adult asthmatics at the Lagos University Teaching Hospital, 80- 488-491. Pediatrics Jan, 81 (1) 1-7.

[26] Agin K., Darjani H. (2005). Blood Serum Magnesium Values in Chronic Stable Asthmatic Patients: A Case - Control Study. 4 (13), 27-32

[27] Wang, J. L. Shaw, N. S. \& Kao, M. D. (2007). Magnesium deficiency and its lack of association with asthma in Taiwanese elementary school children. Asia Pacific journal of clinical nutrition, 16 (S2), 579-584.

[28] Valk, H. Kok, P. Struyvenberg, A. van Rijn, H. Haalboom, H. Kreukniet, J. \& Lammers, J. (1993): Extracellular and intracellular magnesium concentrations in asthmatic patients; 4 (9), 225-245.
[29] Alamoudi OS., (2001). Electrolyte disturbances in patients with chronic, stable asthma: effect of therapy. Chest.; 120 (2): 431-6.

[30] Britton, J. Pavord, I. Richards, K. Wisniewski, A. Knox, A. Lewis, S. \& Tattersfield, A. (1994): Dietary magnesium, lung function, wheezing, and airway hyperreactivity in a random adult population sample.; 344 (8919): 357- 62.

[31] Alamoudi, O. S. (2000). Hypomagnesaemia in chronic, stable asthmatics: prevalence, correlation with severity and hospitalization. European Respiratory Journal, 16 (3), 427431.

[32] Daliparty, V. M., Manu, M. K., \& Mohapatra, A. K. (2018). Serum magnesium levels and its correlation with level of control in patients with asthma: A hospital-based, crosssectional, prospective study. Lung India: official organ of Indian Chest Society, 35 (5), 407.

[33] Knightly, R., Milan, S. J., Hughes, R., Knopp - Sihota, J. A., Rowe, B. H., Normansell, R., \& Powell, C. (2017). Inhaled magnesium sulfate in the treatment of acute asthma. Cochrane Database of Systematic Reviews, (11).

[34] Irazuzta, J. E., \& Chiriboga, N. (2017). Magnesium sulfate infusion for acute asthma in the emergency department. Jornal de pediatria, 93, 19-25. 